\title{
Randomised controlled trial of prophylactic etamsylate: follow up at 2 years of age
}

D Elbourne, S Ayers, H Dellagrammaticas, A Johnson, M Leloup, S Lenoir-Piat, on behalf of the EC Ethamsylate Trial Group

\begin{abstract}
Aim-To assess the role of etamsylate ${ }^{\star}$ in reducing the risk of haemorrhagic brain damage and its consequences.

Design-Follow up of babies recruited into a randomised controlled trial.

Methods-A total of 334 infants born before 33 weeks gestation in France and Greece were randomly allocated within the first four hours of birth either to receive etamsylate or to act as controls. The principal outcomes in the trial were death or impairment and/or disability at the age of 2 years.

Results-Fifty nine children were lost to follow up. A total of 115 (34\%) either died or had some impairment or disability, and $88(26 \%)$ either died or had severe impairment or disability at 2 years of age. These outcomes did not differ significantly between the two randomised groups: relative risks and $95 \%$ confidence intervals 1.14 (0.78 to 1.4$)$ and $1.17(0.82$ to 1.68$)$ respectively. The findings were similar for all the prespecified subgroup analyses stratified by key prognostic factors at trial entry: country of birth, gestational age $<$ or $\geqslant 29$ weeks, inborn or outborn, age $<$ or $\geqslant 1$ hour, and with or without cerebral scan abnormality.

Conclusion-These findings do not support the use of etamsylate. Other strategies need to be evaluated for the prevention of mortality and morbidity in these vulnerable infants.

(Arch Dis Child Fetal Neonatal Ed 2001;84:F183-F187)
\end{abstract}

Medical Statistics Unit, London School of
Hygiene and Tropical Medicine, Keppel Street, London WC1E 7HT, UK D Elbourne

National Perinatal Epidemiology Unit, Institute of Health Sciences, Old Road, Oxford OX3 7LF, UK $S$ Ayers

A Johnson

2nd Department of Pediatrics, Aglaia Kyriakou Children's Hospital, 11527 Athens, Greece $\mathrm{H}$ Dellagrammaticas

Agence Française de Developpement, 5 Rue Roland Barthis, 75012 Paris, France

M Leloup

Clinique de l'union et du Vaurais, Boulevard de Ratalens, 31240

Saint Jean, France

$S$ Lenoir-Piat

Correspondence to:

Dr Elbourne

diana.elbourne@1shtm.ac.uk

Accepted 20 December 2000
Keywords: etamsylate; ethamsylate; preterm; brain; periventricular/intraventricular haemorrhage; childhood disability; randomised controlled trial

Haemorrhagic brain damage (periventricular or intraventricular haemorrhage (PIVH)) is common in infants born early. This damage can lead to death or later impairments and disabilities, with all the consequent burdens on the health services and families. ${ }^{1}$ Preventive measures may be considered in both the antenatal and neonatal periods. Antenatal prevention, however, may reach babies born at term as well as the target preterm population, and so is potentially wasteful of resources. Neonatal interventions to infants actually born preterm therefore have potential advantages.

In the 1980s, the results of two randomised controlled trials ${ }^{23}$ suggested that prophylactic etamsylate may be effective in reducing haemorrhagic damage. Consequently, in 19901991, we conducted an EC funded trial in
France and Greece. In 10 neonatal units, 334 babies born before 33 weeks gestation were randomly allocated within 4 hours of birth to receive either 16 doses of etamsylate over four days or no etamsylate. This was before the surfactant era, and around $25 \%$ of this trial population died or had evidence of major cerebral problems. This outcome did not differ significantly between the two randomised groups (relative risk (RR) 1.17; 95\% confidence interval (CI) 0.82 to 1.65$).{ }^{4}$ Two further trials have been reported. In a trial including 171 babies, $\mathrm{Chen}^{5}$ found a benefit of etamsylate in reducing PIVH and severe PIVH. In contrast, an abstract from a trial of 150 babies did not find any such benefit. ${ }^{6}$

The prespecified principal outcome for the EC trial was not these short term effects, however, but their implications in the longer term. This paper therefore reports the results of a follow up for the surviving children at the age of 2 years.

\section{Methods}

As part of the planned routine follow up in paediatric outpatient clinics of children who had been in neonatal intensive care, it was planned to assess the health and development of surviving children at the age of two years. In France, the paediatrician was "blind" to the treatment allocation and so usually was the paediatrician in Greece.

When a child from the trial was approaching 2 years of age, the parents were asked to bring $\mathrm{him} /$ her to the follow up clinic. They were asked to complete a questionnaire on their child's development and health service usage.

The paediatrician at the clinic recorded information about neuromotor impairment and disabilities, developmental level, seizures, and growth, and then returned the information and the parental questionnaire to Oxford for data processing and analysis. Reminders were sent for any overdue datasheets, and the national coordinators contacted local clinicians.

The principal outcome was death or disability at 2 years. A child was considered to have neuromotor impairment if so classified by the paediatrician and/or there was evidence of increased, decreased, or variable tone. A child who, in addition, was unstable sitting, needed help to walk, or had difficulty using one or both hands was classified as having neuromotor impairment with moderate disability. A child who could not sit unsupported, could not stand

*This is the rINN (Recommended International Non-propriety Name) for ethamsylate. 


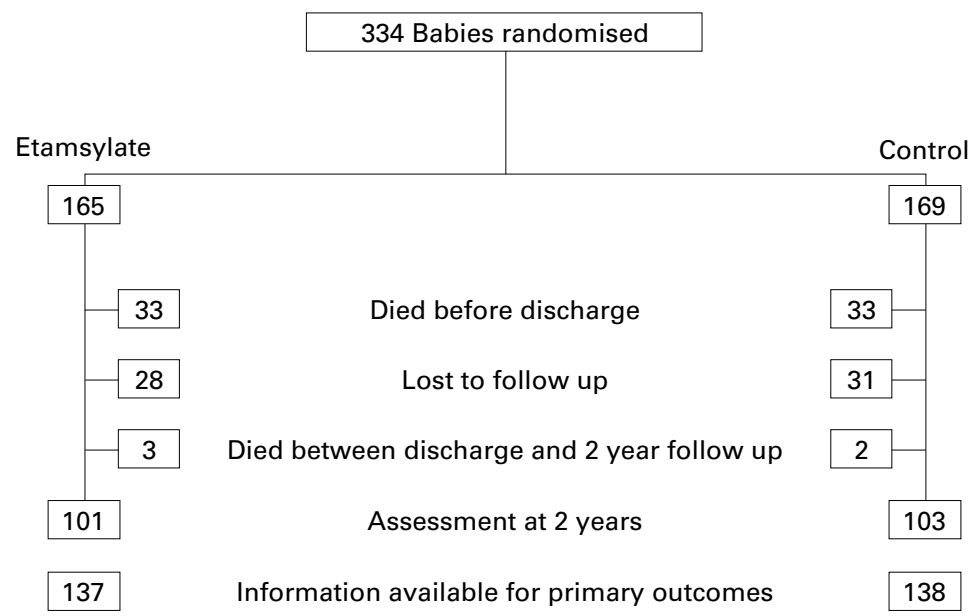

Figure 1 Derivation of children in the 2 year follow up.

or walk, or had very little hand use was classified as having neuromotor impairment with severe disability (functional loss). Developmental delay was classified as mild if less than six months behind, moderate if 6-12 months behind, and severe if more than 12 months behind. Overall, severe disability was defined as neuromotor impairment plus severe functional loss, or severe vision loss, or sensorineural hearing loss with aids, or severe developmental delay.

Primary analyses are based on all babies in the trial, within their randomly allocated groups (intention to treat analysis). Prespecified secondary analyses for the main outcomes are stratified by country, gestational age at trial entry ( $<29$ or $\geqslant 29$ completed weeks), inborn or outborn, age at trial entry ( $\leqslant 1$ or $>1$ hour), and cerebral scan abnormalities known at trial entry. Where appropriate, comparisons are expressed as RRs with 95\% CIs and medians and inter-quartile ranges (IQRs), with the median test.

\section{Results}

Of the 334 babies randomised, 66 (19.8\%) died before discharge from hospital. Fifty nine children $(17.7 \%$ overall or $22.0 \%$ of those discharged alive) were considered to be lost to follow up. The loss was very similar in the two trial arms (fig 1).

Five children $(1.5 \%)$ were known to have died between discharge and the 2 year follow up. The causes of the three deaths in the etamsylate group were given as extensive severe bronchopulmonary dysplasia, sudden death (microcephaly), and possible sudden infant death syndrome. The two deaths in the control group were recorded as sudden death (regurgitation and pulmonary dysplasia, with spastic tetraplegy) and impaction of bowel with strangulated hernia.

Information was available for 204 surviving children at the 2 year follow up. The median age at assessment for both groups was 106 weeks (IQR 103-113). For five children (two receiving etamsylate, three controls), no follow up information was available from the local paediatrician, but was ascertained from the parental questionnaire.

Table 1 gives information about the characteristics of the babies at trial entry and their use of etamsylate, for all those randomised and for those assessed. Those who died were more likely than the survivors to have been of lower birth weight and shorter gestational age, to have had cerebral problems on ultrasound, and to have not completed the full 16 dose course of etamsylate. The children lost to follow up did not differ significantly between the two trial arms, and seemed more similar to those assessed at 2 years of age than to those who died (data available but not shown).

ASSESSMENT AT 2 YEARS OF AGE

Some $14 \%$ of those assessed had some neuromotor impairment, $9.3 \%$ had neuromotor impairment with moderate or severe motor

Table 1 Comparison of all randomised, and survivors assessed at 2 years of age: characteristics at trial entry and etamsylate use

\begin{tabular}{|c|c|c|c|c|}
\hline & \multicolumn{2}{|c|}{ All randomised } & \multicolumn{2}{|l|}{ Assessed } \\
\hline & $\begin{array}{l}\text { Etamsylate } \\
(n=165)\end{array}$ & $\begin{array}{l}\text { Control } \\
(n=169)\end{array}$ & $\begin{array}{l}\text { Etamsylate } \\
(n=101)\end{array}$ & $\begin{array}{l}\text { Control } \\
(n=103)\end{array}$ \\
\hline \multicolumn{5}{|l|}{ Country: } \\
\hline France & 90 & 91 & 52 & 54 \\
\hline Greece & 75 & 78 & 49 & 49 \\
\hline \multicolumn{5}{|l|}{ Age at randomisation (min): } \\
\hline$<60$ & 18 & 21 & 10 & 13 \\
\hline $60-119$ & 55 & 46 & 32 & 24 \\
\hline$\geqslant 120$ & 91 & 101 & 59 & 65 \\
\hline Gestational age: $<29$ weeks & 31 & 35 & 17 & 14 \\
\hline Birth weight: $<1500 \mathrm{~g}$ & 114 & 118 & 62 & 70 \\
\hline Sex: male & 84 & 91 & 50 & 56 \\
\hline Plurality: multiples & 37 & 38 & 26 & 25 \\
\hline No with PIVH & 57 & 62 & 32 & 30 \\
\hline No with cerebral problem on scan & 57 & 61 & 33 & 31 \\
\hline No with major cerebral problem on scan & 21 & 21 & 13 & 8 \\
\hline Fetal presentation: cephalic & 98 & 115 & 60 & 72 \\
\hline Mode of delivery: vaginal & 88 & 80 & 52 & 49 \\
\hline Steroids & 31 & 22 & 21 & 14 \\
\hline \multicolumn{5}{|l|}{ Etamsylate doses: } \\
\hline 0 & 4 & 168 & 1 & 102 \\
\hline $1-15$ & 25 & 0 & 3 & 0 \\
\hline 16 & 136 & 1 & 97 & 1 \\
\hline
\end{tabular}

PIVH, Periventricular/intraventricular haemorrhage. 
Table 2 Survivors assessed at 2 years: neuromotor impairment and developmental status, vision, hearing and medical problems, and growth

\begin{tabular}{|c|c|c|}
\hline & $\begin{array}{l}\text { Etamsylate } \\
(n=101)\end{array}$ & $\begin{array}{l}\text { Control } \\
(n=103)\end{array}$ \\
\hline \multicolumn{3}{|l|}{ Neuromotor impairment } \\
\hline \multicolumn{3}{|l|}{ Tone changes in } \\
\hline 4 limbs & 8 & 2 \\
\hline 3 limbs & 3 & 0 \\
\hline \multicolumn{3}{|l|}{2 limbs } \\
\hline Ipsilateral & 1 & 2 \\
\hline Contralateral & 3 & 4 \\
\hline $1 \mathrm{limb}$ & 1 & 1 \\
\hline $\begin{array}{l}\text { Tone change present but } \\
\text { unclassifiable }\end{array}$ & 1 & 3 \\
\hline No neuromotor impairment & 81 & 89 \\
\hline Not known & 3 & 4 \\
\hline \multicolumn{3}{|l|}{ Neuromotor impairment \pm disability } \\
\hline Impairment but no disability & 5 & 5 \\
\hline Moderate disability & 7 & 5 \\
\hline Severe disability & 5 & 2 \\
\hline \multicolumn{3}{|l|}{ Developmental status } \\
\hline No delay & 87 & 85 \\
\hline Mild delay & 4 & 7 \\
\hline Moderate delay & 3 & 4 \\
\hline Severe delay & 5 & 3 \\
\hline Not known & 2 & 4 \\
\hline \multicolumn{3}{|l|}{ Visionlocular problems } \\
\hline Squint & 19 & 15 \\
\hline ROP & 3 & 1 \\
\hline Refractive error & 5 & 2 \\
\hline Other & 1 & 0 \\
\hline Normal vision & 90 & 88 \\
\hline Not fully corrected by glasses & 0 & 1 \\
\hline Low vision & 1 & 1 \\
\hline See light only or blind & 1 & 0 \\
\hline Not known & 9 & 13 \\
\hline \multicolumn{3}{|l|}{ Hearing } \\
\hline Sensorineural hearing loss: & 1 & 0 \\
\hline Conductive hearing loss & 1 & 0 \\
\hline Hearing aids & 0 & 0 \\
\hline Seizures or on anticonvulsants & 3 & 3 \\
\hline \multicolumn{3}{|l|}{ Drug treatment } \\
\hline Bronchodilators & 7 & 12 \\
\hline Other medication & 5 & 6 \\
\hline \multicolumn{3}{|l|}{ Weight } \\
\hline$<3$ rd centile & 20 & 17 \\
\hline 3-10th centile & 16 & 18 \\
\hline 10-90th centile & 56 & 50 \\
\hline$>90$ th centile & 2 & 2 \\
\hline Not known & 7 & 16 \\
\hline \multicolumn{3}{|l|}{ Length } \\
\hline$<3$ rd centile & 18 & 22 \\
\hline $3-10$ th centile & 18 & 14 \\
\hline 10-90th centile & 58 & 56 \\
\hline$>90$ th centile & 3 & 3 \\
\hline Not known & 4 & 8 \\
\hline \multicolumn{3}{|c|}{$\begin{array}{l}\text { Growth estimates based on Growth Foundation Standards } \\
\text { (Cole TJ, Freeman JV, Preece MA. British } 1990 \text { growth } \\
\text { reference centiles for weight, height, body mass index and head } \\
\text { circumference fitted by maximum penalized likelihood. Stat } \\
\text { Med } 1998 ; 17: 407-29) \text {. } \\
\text { ROP, Retinopathy of immaturity. }\end{array}$} \\
\hline
\end{tabular}

disability, and $7.3 \%$ were classified as having moderate or severe developmental delay (table 2). Differences between the randomised groups were not significant as shown by RRs and $95 \%$ CIs of 1.44 (0.73 to 2.67), 2.04 (0.80 to 5.23 ), and 1.17 (0.44 to 3.09 ) respectively.

Thirty four children had squints, but only two children in each trial arm had poor vision, and none wore hearing aids. Six had seizures or were taking anticonvulsant medication, and 30 had some medication (mainly bronchodilators). There was no evidence of statistically significant differences between the two trial groups. Over a third of the children in both groups were below the 10 th centile for height and weight (table 2).

Table 3 shows the overall status of these children in mutually exclusive categories. Most (145) were assessed as "normal", and a further eight had neuromotor impairment without
Table 3 Survivors assessed at 2 years: overall status (mutually exclusive categories)

\begin{tabular}{|c|c|c|}
\hline & $\begin{array}{l}\text { Etamsylate } \\
(n=101)\end{array}$ & $\begin{array}{l}\text { Control } \\
(n=103)\end{array}$ \\
\hline Normal & 73 & 72 \\
\hline $\begin{array}{l}\text { Neuromotor impairment with no } \\
\text { disability }\end{array}$ & 5 & 3 \\
\hline \multicolumn{3}{|l|}{ Neuromotor impairment } \\
\hline With moderate disability & 2 & 3 \\
\hline $\begin{array}{l}\text { With severe disability but no } \\
\text { impairment in other systems }\end{array}$ & 1 & 1 \\
\hline $\begin{array}{l}\text { With severe disability (other } \\
\text { systems not known) }\end{array}$ & 1 & 0 \\
\hline \multirow{2}{*}{\multicolumn{3}{|c|}{$\begin{array}{l}\text { No neuromotor impairment but disability in other fields } \\
\text { Deafness }\end{array}$}} \\
\hline & & \\
\hline Vision loss & $\begin{array}{l}1 \\
0\end{array}$ & 0 \\
\hline Severe & 1 & 0 \\
\hline \multicolumn{3}{|l|}{ Global developmental delay } \\
\hline Mild & 1 & 6 \\
\hline Moderate & 2 & 3 \\
\hline Severe & 0 & 0 \\
\hline \multicolumn{3}{|l|}{ Multiple system involvement } \\
\hline $\begin{array}{l}\text { Neuromotor impairment }( \pm \\
\text { disability) with impairment in } \\
\text { other fields }\end{array}$ & 8 & 5 \\
\hline No overall status available & 6 & 9 \\
\hline Any impairment or disability & 22 & 22 \\
\hline Severe disability & 11 & 6 \\
\hline
\end{tabular}

Table 4 Survivors assessed at 2 years: health service use between discharge and 2 years

\begin{tabular}{lll}
\hline & $\begin{array}{l}\text { Etamsylate } \\
(n=101)\end{array}$ & $\begin{array}{l}\text { Control } \\
(n=103)\end{array}$ \\
\hline Visits to specialists & 49 & \\
$\quad$ Paediatrician & 54 & 54 \\
Eye specialist & 26 & 22 \\
Ear specialist & 33 & 36 \\
Neurologist & 8 & 17 \\
Surgeon & 31 & 22 \\
Physiotherapist & 2 & 0 \\
$\quad$ Speech therapist & & \\
Hospital re-admissions & 19 & 21 \\
1 & 19 & 18 \\
$\geqslant 2$ & &
\end{tabular}

functional loss. Twenty one had neuromotor impairment with disability or with impairment(s) in other domains.

Over a third of these children were readmitted to hospital, and about half had outpatient visits to paediatricians and/or eye specialists (table 4).

PRINCIPAL OUTCOMES

In terms of the principal outcome, $35.2 \%$ of children in the etamsylate group either died or had some impairment or disability, compared with $33.7 \%$ in the control group (table 5; RR $1.14 ; 95 \%$ CI 0.78 to 1.4 ). If this composite outcome is restricted to those with severe problems - that is, death or severe disability there is still little evidence of a substantial benefit of a policy of neonatal etamsylate (45/ 165 v 39/169; RR 1.17 ; 95\% CI 0.82 to 1.68 ). This conclusion is similar in each of the stratified analyses in table 5 (interaction tests $\mathrm{p}>0.05$ )

Only if we were to make extreme assumptions such as that $60 \%$ or more of those in the control group and none in the etamsylate group (or $100 \%$ in the controls and $40 \%$ in the etamsylate group) had adverse outcomes would we be able to show any statistically significant benefit of etamsylate. 
Table 5 Principal outcomes: for total trial population, and stratified by country, completed weeks gestation at delivery, inborn/outborn, age at entry, and with or without cerebral scan abnormality at trial entry

\begin{tabular}{|c|c|c|}
\hline & $\begin{array}{l}\text { Etamsylate } \\
(n=165)\end{array}$ & $\begin{array}{l}\text { Control } \\
(n=169)\end{array}$ \\
\hline Known death or impairment or disability & $58 / 165(35)$ & $57 / 169(34)$ \\
\hline France & $33 / 90(37)$ & 30/91 (33) \\
\hline Greece & $25 / 75(33)$ & $27 / 78(35)$ \\
\hline$<29$ completed weeks gestation at delivery & $18 / 31(58)$ & $18 / 35(51)$ \\
\hline$=29$ completed weeks gestation at delivery & $40 / 134(29)$ & $39 / 134(29)$ \\
\hline Inborn & $18 / 62(29)$ & $25 / 73(34)$ \\
\hline Outborn & $40 / 103(39)$ & $32 / 96(33)$ \\
\hline \multicolumn{3}{|l|}{ Age at entry } \\
\hline$<1$ hour & $6 / 21(29)$ & $10 / 23(43)$ \\
\hline$\geqslant 1$ hour & $51 / 143(36)$ & $47 / 145(32)$ \\
\hline Not known & $1 / 1(100)$ & $0 / 1(0)$ \\
\hline With cerebral scan abnormality at trial entry & $23 / 57(40)$ & $30 / 61(49)$ \\
\hline Without cerebral scan abnormality at trial entry & $35 / 108(32)$ & $27 / 108(25)$ \\
\hline Known death or severe impairment or disability & $47 / 165(28)$ & $41 / 169(24)$ \\
\hline France & $25 / 90(28)$ & $19 / 91(21)$ \\
\hline Greece & $22 / 75(29)$ & $22 / 78(28)$ \\
\hline$<29$ completed weeks gestation at delivery & $15 / 31(48)$ & $17 / 35(49)$ \\
\hline$=29$ completed weeks gestation at delivery & $32 / 134(24)$ & $24 / 134(18)$ \\
\hline Inborn & $15 / 62(24)$ & $20 / 73(27)$ \\
\hline Outborn & $32 / 103(31)$ & $21 / 96(22)$ \\
\hline \multicolumn{3}{|l|}{ Age at entry } \\
\hline$<1$ hour & $5 / 21(24)$ & $7 / 23(30)$ \\
\hline$\geqslant 1$ hour & $41 / 143(29)$ & $34 / 145(23)$ \\
\hline Not known & $1 / 1(100)$ & $0 / 1(0)$ \\
\hline With cerebral scan abnormality at trial entry & $20 / 57(35)$ & $22 / 61(36)$ \\
\hline Without cerebral scan abnormality at trial entry & $27 / 108(25)$ & $19 / 108(18)$ \\
\hline
\end{tabular}

Values in parentheses are percentages.

\section{Discussion}

Etamsylate prevents capillary bleeding during surgery for adults, and therefore may reduce PIVH in preterm neonates. Horbar ${ }^{7}$ has summarised possible mechanisms of action in terms of stabilisation of capillary membranes and an increase in platelet adhesiveness. It may also have direct effects on the cerebral vasculature by inhibiting prostaglandin synthesis, and indirect effects by closing the patent ductus arteriosus, as suggested in a small trial by Amato et al. . $^{\text {. }}$

The importance of PIVH is as a predictor of longer term outcomes. In this study, $31 \%$ of the 268 babies who had survived to the time of discharge from hospital had been diagnosed with PIVH (with the remainder either known not to have such haemorrhaging or whose haemorrhage status was not known). The status at 2 years of age of 74 of the 268 was not known. On the basis of the remaining 194 children, a diagnosis of PIVH did not appear to significantly raise the risk of the primary adverse outcomes used in the trial. The risk of death or severe impairment or disability was $13.3 \%(8 / 60)$ in the PIVH group compared with $10.4 \%(14 / 134)$ in those without such a diagnosis (RR 1.2; 95\% CI 0.66 to 2.19). Similarly, the risks of death or any impairment or disability were $30 \%(18 / 60)$ compared with $23.1 \%$ (31/134) (RR $1.27 ; 95 \%$ CI 0.81 to 1.98). Given the imperfect predictive value of PIVH as the main outcome for this trial, the follow up reported here clearly adds useful information about longer term implications of interventions in the neonatal period. This paper is currently the only published follow up from a trial of neonatal etamsylate. Provisional findings from the four year follow up from the UK multicentre trial were reported in abstract ${ }^{9}$ but not published in full.

\section{Key messages}

- The findings from the only published follow up of children from a randomised controlled trial of etamsylate do not support its use when given within the first four hours of birth to infants born before 33 weeks gestation

- Centres in Greece and France recruited 334 infants into the trial, and did not find that etamsylate reduced the risk of haemorrhagic brain damage or its consequences in terms of death or impairment and/or disability

- Other strategies need to be evaluated for the prevention of mortality and morbidity in these vulnerable infants

A third of the children in the EC trial died or were classified as having an impairment or disability at the age of 2 years. There is little evidence from this trial, however, that a policy of neonatal etamsylate would reduce the burden on their parents or on the health services.

There are a number of possible reasons for this finding. It could be that more children in the control group who were lost to follow up suffered an adverse outcome. This seems unlikely given the similarity in loss to follow up between the randomised groups.

It could be that a potential lack of blinding to allocation in Greece led to a bias in the paediatrician's assessment of the child's status. Again, this seems unlikely, partly because such bias was more likely to be in favour of etamsylate (the experimental treatment), and partly because the findings in France and Greece are similar.

Another possibility could be that the beneficial effects of etamsylate were diluted because it was not given soon enough after birth. This hypothesis is not supported by the analysis stratified by age at randomisation.

Perhaps the trial population, by including babies who, at 31 and 32 weeks gestation, had a relatively high chance of a good outcome, was not at sufficiently high risk. This seems unlikely to be a reason because about a third of the babies had a bad outcome, and the analysis stratified by gestational age did not suggest a greater effect in the lower gestational age group.

Alternatively, perhaps the population was at too high a risk, given that nearly a third already had cerebral problems on scans at the time of trial entry. Analysis of the primary outcomes stratified by known cerebral problems were, however, unable to detect a significant benefit of etamsylate.

It may be that, had the assessment been performed by a research developmental paediatrician in the child's home rather than in a normal follow up clinic, more subtle effects may have been detected. However, this would apply equally to babies in both trial arms.

Although this is the largest trial of neonatal etamsylate, it may still not be powerful enough 
to detect uncommon effects. The $95 \%$ confidence intervals are still wide and so can only exclude the possibility of a benefit if it was less than about $20-25 \%$.

The most likely reason for not being able to detect a sizeable benefit of the etamsylate policy in this trial is that such a benefit does not exist. Alternative strategies such as neonatal indomethacin ${ }^{10}$ and delayed umbilical cord clamping ${ }^{11}$ still need to be evaluated in well designed studies.

We would like to thank all the participants in the original trial and in the follow up, especially the families of the children.

The EC Ethamsylate Trial Group included the following.

Clinical collaborators:

France: Lille, CHU A Calmette (Professor P Lequien, Dr N Kacet); Toulouse, Hôpital Purpan (Professor M Rolland, Dr H Descoing); Nice, Hôpital de Cimiez (Professor P Boutté, D Berard); Arras, Centre Hôpitalier (Dr O Dubois, Dr B Théret)

Greece: Athens, Alexandra Maternity Hospital (Dr A Kapiki, Dr C Papas); Helena Veniselou Maternity Hospital (Dr J Sofatzis, Dr M Tzaki); Damon Vasiliou General Hospital (Dr C Costalos, Dr J Lambadaridis); "B" NICU Aghia Sophia Children's Hospital (Dr M Xanthou, Dr M Anagnastokou); "A" NICU Aghia Sophia Children's Hospital (Dr N Kalpoyiannis, Dr A Charitou); Aglaia Kyriakou Children's Hospital (Dr H Dr A Charitou); Aglaia Kyriakou Chich

Central coordination: The following were responsible for different aspects of coordination:

different aspects of coordination:
United Kingdom: Diana Elbourne, Adrian Grant, Lesley United Kingdom: Diana Elbourne, Adrian Grant, Lesley
Mireh (Morgan), Carole Harris, Jean Fooks, Sarah Ayers, (PeriMireh (Morgan), Carole Har
natal Trials Service, Oxford).

France: Madeleine Leloup, Sylvie Lenoir, Helene Grandjean (INSERM CJF 89-08, Toulouse).

Greece: Heracles Dellagrammaticas (2nd Department of Pediatrics, University of Athens, Aglaia Kyriakou Children's Hospital, Athens)

EC project management group (especially Monique Kaminski and Pauline Verloove-Vanhorick).
The EC provided funding for central coordination, and the Perinatal Trials Service was supported by the Department of Health, London.

1 Stevenson RC, Pharoah POD, Stevenson CJ, et al. Cost of care for a geographically determined population of low birthweight infants to age 8-9 years. II. Children with disability. Arch Dis Child Fetal Neonatal Ed 1996;74:F118-21.

2 Morgan MEI, Benson JWT, Cooke RWI. Ethamsylate reduces the influence of periventricular haemorrhage in very low birth-weight babies. Lancet 1981;ii:830-1.

3 Benson JWT, Drayton MR, Hayward C, et al. Multicentre trial of ethamsylate for prevention of periventricular haemorrhage in very low birthweight babies. Lancet 1986;ii: $1297-300$.

4 The EC Ethamsylate Trial Group. The EC randomised controlled trial of prophylactic ethamsylate for very preterm neonates: early mortality and morbidity. Arch Dis Child Fetal Neonatal Ed 1994;70:F201-5.

5 Chen JY. Ethamsylate in the prevention of prevention periventricular-intraventricular haemorrhage in premature infants. F Formos Med Assoc 1993;92:889-93.

6 Sanghvi KP, Merchant RH, Kulkarni. Efficacy of ethamsylate in prevention periventricular-intraventricular haemorrhage in newborns < 34 weeks gestation [abstract 1124]. Pediatr Res 1998;193.

7 Horbar JD. Prevention of periventricular-intraventricular hemorrhage. In: Sinclair JC, Bracken MB, eds. Effective care of the newborn infant. Oxford: Oxford University Press, 1992:562-89.

8 Amato M, Huppi P, Markus D. Prevention of symptomatic patent ductus arteriosus with ethamsylate in babies treated with exogenous surfactant. F Pediatr 1993;13:2-7.

9 Schulte JF, Benson JWT, Cooke RWI, et al. The follow-up study to the multicentre trial of ethamsylate for prevention of periventricular haemorrhage [abstract]. Proceedings of the annual meeting of the British Paediatric Association, Warwick, 1991 .

10 Ment L, Oh W, Ehrenkranz R, et al. Low dose indomethacin and prevention of intraventricular haemorrhage: a multicentre randomised trial. Pediatrics 1994;93:543-50.

11 McDonnell M, Henderson-Smart D. Delayed umbilical cord clamping in preterm infants: a feasibility study. F Paediatr Child Health 1997;33:308-10. 